\title{
Materials Advances
}

\section{CORRECTION}

View Article Online

View Journal I View Issue

\section{D) Check for updates \\ Cite this: Mater. Adv., 2020, \\ 1,2137 \\ Correction: Poly( $\mathrm{N}$-isopropyl acrylamide)- poly(ethylene glycol)-poly( $\mathrm{N}$-isopropyl acrylamide) as a thermoreversible gelator for topical administration}

\author{
P. Haddow, W. J. McAuley, S. B. Kirton and M. T. Cook*
}

DOI: 10.1039/d0ma90026e

Correction for 'Poly( $N$-isopropyl acrylamide)-poly(ethylene glycol)-poly( $N$-isopropyl acrylamide) as a thermoreversible gelator for topical administration' by P. Haddow et al., Mater. Adv., 2020, 1, 371-386,

rsc.li/materials-advances DOI: 10.1039/DOMA00080A.

The authors regret that there is a typo in the final paragraph of the 5th page of the article. In the sentence beginning "Of the concentrations studied...", the text in brackets that reads " $T_{\text {gel }}$ of 30 and $5{ }^{\circ} \mathrm{C}$, respectively" should read " $T_{\text {gel }}$ of 30 and $25{ }^{\circ} \mathrm{C}$, respectively".

The Royal Society of Chemistry apologises for these errors and any consequent inconvenience to authors and readers. 